\title{
Effect of gold nanoparticles in the local heating of skin tumors induced by phototherapy
}

\author{
I. Salas-García ${ }^{* a}$, F. Fanjul-Vélez ${ }^{\mathrm{a}}$, N. Ortega-Quijano ${ }^{\mathrm{a}}$, A. Lavín-Castanedo ${ }^{\mathrm{a}}$, P. Mingo-Ortega ${ }^{\mathrm{a}}, \mathrm{M}$. \\ López-Escobar ${ }^{\mathrm{b}}$, J. L. Arce-Diego*a \\ ${ }^{a}$ Applied Optical Techniques Group, TEISA Department, University of Cantabria \\ Av. de los Castros S/N, 39005 Santander (Spain) \\ ${ }^{\mathrm{b}}$ Dermatology Department, Marqués de Valdecilla University Hospital, Av. Valdecilla S/N, \\ 39008 Santander (Spain)
}

\begin{abstract}
During optical therapies, several types of interaction between the optical radiation and the target tissue can occur. The application of different power densities and the variation of the exposure time can cause from photochemical reactions to photodisruption. Photothermal therapy (PTT) is based in the thermal interactions, where the biological injury is provoked by a given increase of their temperature during the exposition to the optical source. Another treatment option very extended in several clinical fields due to its promising results is Photodynamic Therapy. This treatment modality is based in photochemical reactions where it is also required oxygen and the administration of a photosensitive substance known as photosensitizer.

The use of nanotechnology in optical therapeutic techniques, constitutes a novel promising treatment strategy. Specifically, gold nanoparticles can improve different issues related to the transport of photosensitizers or the light energy absorption and the subsequent heat generation. This work focuses in the effects that can produce the use of gold nanoparticles in Photothermal and Photodynamic Therapies applied to skin diseases commonly treated by means of these techniques. We present a thermal model that permits to calculate the temperature distribution in different kinds of pathological dermatological tissues depending on the optical power provided by the optical source. The results obtained permit to compare the thermal injury produced depending on not only the provided power but also the type of pathology and the incorporation or not of gold nanoparticles in the target tissue.
\end{abstract}

Keywords: Photothermal therapy, photodynamic therapy, nanoparticles, skin diseases.

\section{INTRODUCTION}

In recent years a strong interest has emerged related to the use of nanoparticles (NPs) in the clinical practice to improve the actual diagnostic and therapeutic techniques such as Photothermal and Photodynamic Therapies [1]. The development of models to obtain the NPs distribution as well as those, [2], to obtain optical and thermal effects induced by their incorporation in the target tissue are very important to adjust the treatment dosimetry of these new treatment modalities, [3, 4]. However, as important as these aspects, is the type of pathology subjected to treatment that influences in the optical radiation distribution and in the thermal effects provoked as a consequence of light absorption.

This work focuses in the use of gold NPs to improve the actual optical radiation distribution and its effects in the local heating of different skin diseases treated by Photothermal and Photodynamic Therapies. In section 2 we present the optothermal model used. Once optical radiation distribution into the tissue with embedded NPs is obtained, we use a thermal model which allows us to calculate the temperature profile. Finally, the obtained results and their discussion are presented in the section 3 and the conclusions are contained in section 4.

\footnotetext{
*isalas@teisa.unican.es ; arcedj@unican.es ; phone +34942201545; fax +34942201873 www.teisa.unican.es/toa

Medical Laser Applications and Laser-Tissue Interactions V, edited by Ronald Sroka, Lothar D. Lilge, Proc. of SPIE-OSA Biomedical Optics, SPIE Vol. 8092, 809204

(C) 2011 SPIE-OSA - CCC code: $1605-7422 / 11 / \$ 18 \cdot$ doi: $10.1117 / 12.889830$
} 


\section{OPTOTHERMAL MODEL}

In order to know the temperature distribution in the target tissue, first the optical radiation is obtained by means of the Radiation Transport Theory, taking into account the pathological tissue absorption and scattering coefficients as well as those induced by NPs and calculated by means of Mie's theory. Then, it is possible to study thermal effects from radiation absorption in each point using the bio-heat equation.

\subsection{Distribution of the optical radiation}

Modeling the optical radiation distribution in a biological tissue implies dealing with an heterogeneous medium, which does not allow an analytic exact approach of the radiation pattern with Maxwell equations. For the problem we are dealing with, the distribution of light in a three-dimensional tissue must be obtained. This objective is reached by means of the Radiation Transport Theory (RTT) [5] applying a multilayer implementation of the Monte Carlo Method developed by Wang and Jacques [6,7]. The basic parameter of light is the specific intensity, $I(r, \hat{\mathrm{s}})$. The radiation is expected to be at the point $\overrightarrow{\mathrm{r}}$, and to follow the direction $\hat{\mathrm{s}}$. The scattering events are treated according to the scattering phase function, $\mathrm{p}\left(\hat{\mathrm{s}} \cdot \hat{\mathrm{s}}^{\prime}\right)$, which contains the probabilities of light to be scattered in the different directions.

Optical radiation comes from direction $\hat{\mathrm{s}}^{\prime}$ and is redirected to $\hat{\mathrm{s}}$. The basic idea in order to write the differential radiation transport equation is that radiation from a particle attenuates due to absorption and scattering and also gains power because another particle can scatter light in the direction of the particle of interest. This, with no sources inside the tissue and a steady-state situation, can be written as

$$
\hat{\mathrm{s}} \cdot \bar{\nabla} \mathrm{I}(\mathrm{r}, \hat{\mathrm{s}})=-\left(\mu_{\mathrm{a}}+\mu_{\mathrm{s}}\right) \mathrm{I}(\mathrm{r}, \hat{\mathrm{s}})+\frac{\mu_{\mathrm{s}}}{4 \pi} \int_{4 \pi} \mathrm{p}\left(\hat{\mathrm{s}} \cdot \hat{\mathrm{s}}^{\prime}\right) \mathrm{I}\left(\mathrm{r}, \hat{\mathrm{s}}^{\prime}\right) \mathrm{d} \Omega^{\prime} .
$$

The absorption and scattering events which suffers optical radiation as propagate through the biological medium with embedded NPs must take into account contributions from optical properties depending on the type of pathological tissue and from NPs. In order to quantify both contributions, absorption and scattering coefficients, $\mu_{\mathrm{a}}$ and $\mu_{\mathrm{s}}$, were calculated as

$$
\begin{aligned}
& \mu_{\mathrm{a}}=\mu_{\mathrm{aNP}}+\mu_{\mathrm{apt}}, \\
& \mu_{\mathrm{s}}=\mu_{\mathrm{sNP}}+\mu_{\mathrm{spt}},
\end{aligned}
$$

where the subscript NP indicates properties of nanoparticles and the subscript pt indicates properties of the pathological tissue.

In NP assisted PDT the optical response of tissues varies depending on the type and size of the NP embedded in the target tissue, [8]. In order to get the optical absorption and scattering properties of gold nanospheres with a radius of 80 and $100 \mathrm{~nm}$ for the laser wavelengths in the red region of the visible spectrum $(630-635 \mathrm{~nm})$, we calculate the efficiency factors of absorption Qabs, scattering Qsca and extinction Qext by means of Mie's theory for an homogeneous spherical $\mathrm{NP}$ with radius $\mathrm{r}$ and complex refractive index of gold $\mathrm{m}$, [9], as

$$
\begin{gathered}
\mathrm{Q}_{\text {sca }}=\frac{2}{\mathrm{x}^{2}} \sum_{\mathrm{n}=1}^{\infty}(2 \mathrm{n}+1)\left(\left|\mathrm{a}_{\mathrm{n}}\right|^{2}+\left|\mathrm{b}_{\mathrm{n}}\right|^{2}\right), \\
\mathrm{Q}_{\mathrm{ext}}=\frac{2}{\mathrm{x}^{2}} \sum_{\mathrm{n}=1}^{\infty}(2 \mathrm{n}+1) \operatorname{Re}\left(\mathrm{a}_{\mathrm{n}}+\mathrm{b}_{\mathrm{n}}\right), \\
\mathrm{Q}_{\mathrm{abs}}=\mathrm{Q}_{\mathrm{ext}}-\mathrm{Q}_{\mathrm{sca}} .
\end{gathered}
$$

The amplitude coefficients $a_{n}$ and $b_{n}$ for the scattered field, which involve spherical Bessel functions [10], the refractive index of the sphere relative to the ambient medium and the size parameter $\mathrm{x}=\mathrm{kr}$, have been calculated as 


$$
\begin{gathered}
a_{n}=\frac{m^{2} j_{n}(m x)\left[x j_{n}(x)\right]^{\prime}-\mu_{1} j_{n}(x)\left[m x j_{n}(m x)\right]^{\prime}}{m^{2} j_{n}(m x)\left[x h_{n}^{(1)}(x)\right]^{\prime}-\mu_{1} h_{n}^{(1)}(x)\left[m x j_{n}(m x)\right]^{\prime}}, \\
b_{n}=\frac{\mu_{1} j_{n}(m x)\left[x j_{n}(x)\right]^{\prime}-j_{n}(x)\left[m x j_{n}(m x)\right]^{\prime}}{\mu_{1} j_{n}(m x)\left[x h_{n}^{(1)}(x)\right]^{\prime}-h_{n}^{(1)}(x)\left[m x j_{n}(m x)\right]^{\prime}},
\end{gathered}
$$

where $\mathrm{k}=2 \pi / \lambda$ is the wave number, $\lambda$ is the wavelength in the ambient medium and $\mu_{1}$ is the ratio of the magnetic permeability of the sphere to the magnetic permeability of the ambient medium.

NP absorption and scattering coefficients are quantified from efficiency parameters, cross section of the spherical NP and the number of NPs per unit volume by the following expressions

$$
\begin{aligned}
& \mu_{\text {abs }}=\pi r^{2} \mathrm{Q}_{\text {abs }} \mathrm{N}_{\mathrm{T}}, \\
& \mu_{\text {sca }}=\pi \mathrm{r}^{2} \mathrm{Q}_{\text {sca }} \mathrm{N}_{\mathrm{T}} .
\end{aligned}
$$

\subsection{Thermal distribution}

Once the optical distribution in the tissue is obtained it is possible to study the thermal effects that are produced from radiation absorption in each point. The main heat mechanisms that will be considered are [11]: conduction (the diffusion of heat in a solid from hot regions to colder ones), convection (interaction between a solid surface and a fluid in contact with it) and radiation (heat transport due to the infrared emission of a body at a nonzero temperature). The main objective is to obtain a differential equation that describes the spatial and temporal behavior of the tissue temperature (i.e., the bio-heat equation). Firstly, we take the balance equation for the thermal energy:

$$
\mathrm{Q}_{\text {gain }}=\mathrm{Q}_{\text {storage }}+\mathrm{Q}_{\text {loss }} \text {. }
$$

Each element of (2) admits an integral expression, and the final expression is given by:

$$
\int_{V} \mathrm{q}(\overrightarrow{\mathrm{r}}, \mathrm{t}) \mathrm{dV}=\int_{\mathrm{V}} \rho \mathrm{c} \frac{\mathrm{dT}(\overrightarrow{\mathrm{r}}, \mathrm{t})}{\mathrm{dt}} \mathrm{dV}-\int_{\mathrm{S}} \mathrm{k} \nabla \mathrm{T}(\overrightarrow{\mathrm{r}}, \mathrm{t}) \hat{\mathrm{n}} \mathrm{dS}-\int_{\mathrm{V}} \rho_{\mathrm{b}} \mathrm{c}_{\mathrm{b}} \mathrm{w}_{\mathrm{b}}\left[\mathrm{T}_{\mathrm{art}}(\overrightarrow{\mathrm{r}}, \mathrm{t})-\mathrm{T}_{\text {ven }}(\overrightarrow{\mathrm{r}}, \mathrm{t})\right] \mathrm{dV},
$$

where $q(\vec{r}, t)$ is the volumetric heat generated in position $\vec{r}$ at time $t$. The absolute temperature is given by $T$, in a tissue of density $\rho\left[\mathrm{kg} / \mathrm{m}^{3}\right]$ and specific heat $\mathrm{c}[\mathrm{J} / \mathrm{Kg} \cdot \mathrm{K}]$. It is assumed that the internally generated heat is negligible. Parameter $\mathrm{k}[\mathrm{W} / \mathrm{m} \cdot \mathrm{K}]$ is the thermal conductivity, that governs the losing effect of conduction. The convection effect caused by blood perfusion in living tissues is modeled by the volumetric perfusion $\mathrm{w}_{\mathrm{b}}\left[\mathrm{m}_{\mathrm{b}}{ }^{3} / \mathrm{s} \cdot \mathrm{kg}_{\text {tissue }}\right]$, as well as by the venous and arterial temperatures.

The resolution of the bio-heat equation is performed by the finite element method, so that the temperature distribution in space and time can be obtained. It should be remarked that the boundary conditions must be carefully defined. The model comprises a wide range of effects and entails a considerable complexity, giving a realistic approach for the study of thermal effects it tissues.

\section{RESULTS AND DISCCUSION}

The efficiency factors of absorption $\mathrm{Q}_{\mathrm{abs}}$, scattering $\mathrm{Q}_{\text {sca }}$ and extinction $\mathrm{Q}_{\mathrm{ext}}$ for gold nanoparticles (radius of 80 and 100 $\mathrm{nm}$ ) were obtained by means of Mie's theory. The results are presented in Fig. 1 a) for nanoparticles with a radius of 80 $\mathrm{nm}$ and in Fig. 1b) for nanoparticles with a radius of $100 \mathrm{~nm}$. Optical absorption and scattering properties of those nanoparticles were calculated at laser wavelengths in the red region of the visible spectrum $(630-635 \mathrm{~nm})$ due to their wide application in phototherapy. 
a)

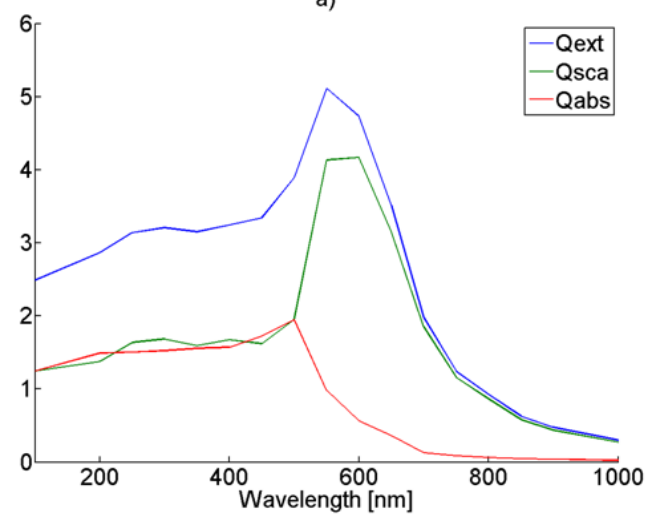

b)

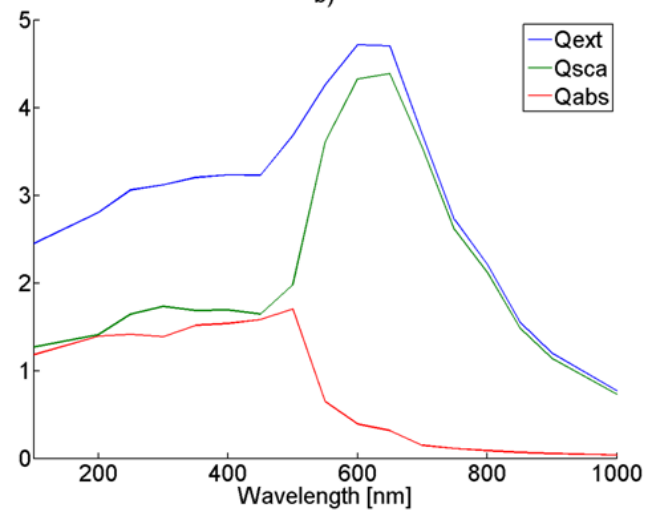

Fig. 1. Efficiency factors of absorption $\mathrm{Q}_{\mathrm{abs}}$, scattering $\mathrm{Q}_{\mathrm{sca}}$ and extinction $\mathrm{Q}_{\mathrm{ext}}$ for nanoparticles with a radius of a) 80 $\mathrm{nm}$ and b) $100 \mathrm{~nm}$.

The optical radiation distribution was obtained by means of the Monte Carlo method previously presented. For the appropriate definition of the model, the characteristics and dimensions of each layer are required. The optical parameters needed are the index of refraction, $\mathrm{n}$, the absorption coefficient, $\mu_{\mathrm{a}}$, the scattering coefficient, $\mu_{\mathrm{s}}$, and the anisotropy of scattering, $g$. The optical parameters used for each layer of the multilayer tissue sample and their width are listed in table 1, for the three types of tumoral tissues used (infiltrative basal cell carcinoma, nodular basal cell carcinoma and squamous cell carcinoma) $[11,12]$.

Table 1. Optical parameters of three types of tumoral tissues (nodular basal cell carcinoma (NBCC), infiltrative basal cell carcinoma (IBCC) and squamous cell carcinoma (SCC)) and healthy tissue (subcutaneous fat) at $633 \mathrm{~nm}$.

\begin{tabular}{|c|c|c|c|c|}
\hline Optical parameters & NBCC & IBCC & SCC & Healthy tissue \\
\hline Scattering coefficient $\left(\mathrm{cm}^{-1}\right)$ & 104.76 & 142.85 & 95.238 & 20 \\
\hline Absorption coefficient $\left(\mathrm{cm}^{-1}\right)$ & 1.5 & 1.5 & 2 & 0.2 \\
\hline Index of refraction & 1.5 & 1.5 & 1.5 & 1.45 \\
\hline Anisotropy of scattering & 0.79 & 0.79 & 0.79 & 0.8 \\
\hline Width (mm) & 1 & 1 & 1 & 0.6 \\
\hline
\end{tabular}

For all of them the optical source power was varied and the temperature distribution was calculated with the thermal model presented in three different situations (without nanopaticles embedded in the tumor and with 80 and $100 \mathrm{~nm}$ nanoparticles embedded). The thermal parameters corresponding to the tumor zone and the healthy tissue below are listed in table 2. 
Table 2. Thermal parameters used for the tumoral and the healthy tissues.

\begin{tabular}{|c|c|c|}
\hline Thermal parameters & Tumor & Healthy tissue \\
\hline Thermal conductivity $[\mathrm{W} / \mathrm{m} \cdot \mathrm{K}]$ & 0.59 & 0.209 \\
\hline Specific heat $[\mathrm{J} / \mathrm{Kg} \cdot \mathrm{K}]$ & $4.2 \cdot 10^{3}$ & $1.96 \cdot 10^{3}$ \\
\hline Volumetric perfusion $\left[\mathrm{m}_{\mathrm{b}}{ }^{3} / \mathrm{s} \cdot \mathrm{kg}_{\text {tissue }}\right]$ & $5 \cdot 10^{-3}$ & $2.98 \cdot 10^{-3}$ \\
\hline Tissue density $\left[\mathrm{kg} / \mathrm{m}^{3}\right]$ & $1 \cdot 10^{3}$ & 850 \\
\hline
\end{tabular}

The temperature profiles have been obtained for three types of skin diseases (nodular basal cell carcinoma, infiltrative basal cell carcinoma and squamuous cell carcinoma) and for these pathologies with $2 \cdot 10^{9} \mathrm{~cm}^{-3}$ spherical gold NPs embedded. Table 3 shows the results obtained, the maximum and medium temperature reached in the three tumoral samples with 80 and 100 gold NPs embedded in the tissue and without them for different optical powers.

Table 3. Maximum and medium temperature reached in three skin tumors with and without gold NPs for different optical powers.

\begin{tabular}{|c|c|c|c|c|c|c|}
\hline Pathology & \multicolumn{2}{|c|}{ Infiltrative BCC } & \multicolumn{2}{|c|}{ Nodular BCC } & \multicolumn{2}{|c|}{ SCC } \\
\hline Temperature & Max. T $\left({ }^{\circ} \mathrm{C}\right)$ & Med. T $\left({ }^{\circ} \mathrm{C}\right)$ & Max. T $\left({ }^{\circ} \mathrm{C}\right)$ & Med. T $\left({ }^{\circ} \mathrm{C}\right)$ & Max. T $\left({ }^{\circ} \mathrm{C}\right)$ & Med. T $\left({ }^{\circ} \mathrm{C}\right)$ \\
\hline \multicolumn{7}{|c|}{$0.1 \mathrm{~W}$} \\
\hline Without NPs & 37.1096 & 37.0091 & 37.0995 & 37.0085 & 37.1213 & 37.0117 \\
\hline NP $80 \mathrm{~nm}$ & 37.1232 & 37.0107 & 37.1125 & 37.0102 & 37.1328 & 37.0130 \\
\hline NP $100 \mathrm{~nm}$ & 37.1248 & 37.0109 & 37.1137 & 37.0104 & 37.1342 & 37.0131 \\
\hline \multicolumn{7}{|c|}{$3.1 \mathrm{~W}$} \\
\hline Without NPs & 41.2701 & 37.6666 & 40.8312 & 37.6494 & 41.5567 & 37.7474 \\
\hline $\mathrm{NP} 80 \mathrm{~nm}$ & 41.7520 & 37.7191 & 41.2812 & 37.7035 & 41.9629 & 37.7889 \\
\hline NP $100 \mathrm{~nm}$ & 41.8090 & 37.7247 & 41.3327 & 37.7087 & 42.0137 & 37.7934 \\
\hline \multicolumn{7}{|c|}{$3.3 \mathrm{~W}$} \\
\hline Without NPs & 41.5492 & 37.7104 & 41.0820 & 37.6921 & 41.8542 & 37.7964 \\
\hline $\mathrm{NP} 80 \mathrm{~nm}$ & 42.0622 & 37.7664 & 41.5610 & 37.7497 & 42.2867 & 37.8407 \\
\hline $\mathrm{NP} 100 \mathrm{~nm}$ & 42.1229 & 37.7723 & 41.6158 & 37.7522 & 42.3407 & 37.8454 \\
\hline \multicolumn{7}{|c|}{$3.6 \mathrm{~W}$} \\
\hline Without NPs & 41.9678 & 37.7762 & 41.4581 & 37.7562 & 42.3006 & 37.8700 \\
\hline NP $80 \mathrm{~nm}$ & 42.5274 & 37.8372 & 41.9807 & 37.8191 & 42.7723 & 37.9183 \\
\hline NP $100 \mathrm{~nm}$ & 42.5936 & 37.8437 & 42.0405 & 37.8250 & 42.8313 & 37.9235 \\
\hline
\end{tabular}

In all the cases the NPs administration to the target tissue promotes a greater increase in tissue temperature, so that the power delivered by the illumination source may be decreased if NPs are present. Thus, the maximum temperature registered in a SCC tumor exceeded the temperature threshold needed to induce thermal effects $\left(42^{\circ} \mathrm{C}\right)$ when $3.6 \mathrm{~W}$ were applied, whereas the $100 \mathrm{~nm}$ Au NPs incorporation reduces that power to $3.1 \mathrm{~W}$ and approximately to $3.3 \mathrm{~W} \mathrm{if} 80 \mathrm{~nm} \mathrm{Au}$ NPs are administered. 
Taking $42{ }^{\circ} \mathrm{C}$ as the temperature threshold needed to induce thermal effects in the tissue, it can be observed that this will be reached first for the SCC using $100 \mathrm{~nm}$ Au NPs. There were also differences in the optical power needed to induce thermal effects depending on the type of pathology. When an optical power of $3.1 \mathrm{~W}$ was applied, only the SCC sample reached $42{ }^{\circ} \mathrm{C}$ with $100 \mathrm{~nm} \mathrm{Au} \mathrm{NP}$ embedded whereas in the other two skin diseases a higher optical power was applied in order to obtain the same temperature increment.

The results obtained also demonstrate that during Photodynamic Therapy, where small optical powers are applied, thermal effects are not produced in any of the three pathologies. Therefore tumoral tissue necrosis in PDT is a consequence of a photochemical light-tissue interaction and not a thermal interaction.

\section{CONCLUSIONS}

The use of gold nanoparticles enhances the localized absorption of the electromagnetic radiation applied in conventional optical therapies based in light-tissue thermal interactions. In order to predict the thermal response induced by NPs incorporation in skin tissues a thermal response model for three different skin pathologies using gold nanoparticles was presented. The efficiency factors of absorption, scattering and extinction were calculated by means of Mie's theory for homogeneous spherical NPs and complex refractive index of gold which allow us to know the scattering and absorption coefficients needed to obtain light propagation in the tissue samples with NPs embedded by a numerical Monte Carlo method. The temperature distribution in the tissue samples was obtained by means of the bio-heat equation whose resolution was performed by the finite element method.

The results obtained predict the temperature increment produced in photothermal interactions when gold nanoparticles are incorporated in the target tissue. Optical source powers and type of skin pathology were varied. It is shown the great influence of both NPs and type of skin pathology in the adjustment of the optical power needed to induce the desired thermal effect. It was also proved the absence of thermal effects during photodynamic therapy.

\section{ACKNOWLEDGEMENTS}

This work has been partially founded by the Leonardo Torres Quevedo Foundation.

\section{REFERENCES}

[1] Allison, R.R., Mota, H.C., Bagnato, V.S. and Sibata, C.H., "Bio-nanotechnology and photodynamic therapy: State of the art review", Photodiagnosis and Photodynamic Therapy 5, 19-28 (2008).

[2] Goodman, T. T., Chen, J., Matveev, K. and Pun, S. H., "Spatio-Temporal Modeling of Nanoparticle Delivery to Multicellular Tumor Spheroids", Biotechnology and Bioengineering 101(2), 388-399 (2008).

[3] Pustovalov, V., Astafyeva, L. and Jean, B., "Computer modeling of the optical properties and heating of spherical gold and silica-gold nanoparticles for laser combined imaging and photothermal treatment", Nanotechnology 20 225105, 1-11 (2009).

[4] Richardson, H. H., Carlson, M. T., Tandler, P. J., Hernandez, P. and Govorov, A. O., "Experimental and Theoretical Studies of Light-to-Heat Conversion and Collective Heating Effects in Metal Nanoparticle Solutions", Nano Letters 9(3), 1139-1146 (2009).

[5] Vo-Dinh, T., [Biomedical Photonics Handbook], T. Vo-Dinh, ed., CRC Press, Boca Raton (2003).

[6] Wang, L., Jacques, S. L. and Zheng, L., "MCML - Monte Carlo modeling of light transport in multi-layered tissues", Computer methods and programs in biomedicine 47, 131-146 (1995).

[7] Wang, L., Jacques, S. L. and Zheng, L., "CONV - Convolution for responses to a finite diameter photon beam incident on multi-layered tissues", Computer methods and programs in biomedicine 54, 141-150 (1997).

[8] Lance Kelly, K., Coronado, E., Zhao, L. L., and Schatz, G. C., "The Optical Properties of Metal Nanoparticles: The Influence of Size, Shape, and Dielectric Environment”, J. Phys. Chem. B 107, 668-677 (2003).

[9] Bohren, C.F. and Huffman, D.R., [Absorption and Scattering of Light by Small Particles], John Wiley, New York, NY (1983). 
[10] Mätzler, C., "MATLAB Functions for Mie Scattering and Absorption", Universitas Bernensis, (2002).

[11]Fanjul-Vélez, F., Romanov, O. G., Arce Diego, J. L., "Efficient 3D numerical approach for temperature prediction in laser irradiated biological tissues", Computers in Biology and Medicine 39, 810-817 (2009).

[12] Salomatina, E., Jiang, B., Novak, J. and Yaroslavsky, A. N., "Optical properties of normal and cancerous human skin in the visible and near-infrared spectral range", Journal of Biomedical Optics 11(6), 0640261-9 (2006). 